\title{
Synthesis and Characterization of Nickel Oxide Nanostructures for Electrochemical Analysis of Methotrexate
}

\author{
Saeed Ahmed Lakho ${ }^{1 *}$, Mansoor Ahmed ${ }^{1}$, Muhammad Waseem Akhtar², \\ Madan Lal ${ }^{3}$, Ubed-Ur-Rahman Mughal ${ }^{4}$, Umair Aftab ${ }^{2}$, \\ Zafar Hussain Ibupoto ${ }^{5}$ and $\mathrm{Saba} \mathrm{Naz}^{5}$ \\ ${ }^{1}$ Department of Pharmaceutical Chemistry, Faculty of Pharmacy and Pharmaceutical Sciences, \\ University of Karachi, Sindh, Pakistan. \\ ${ }^{2}$ Department of Metallurgy and Materials Engineering, Mehran University of Engineering and Technology, \\ Jamshoro, Sindh, Pakistan. \\ ${ }^{3}$ Department of Pharmaceutical Chemistry, University of Sindh, Jamshoro, Sindh, Pakistan. \\ ${ }^{4}$ Department of Pharmaceutics, University of Sindh, Jamshoro, Sindh, Pakistan. \\ ${ }^{5}$ Dr. M. A. Kazi Institute of Chemistry, University of Sindh, Jamshoro, Sindh, Pakistan. \\ *Corresponding Author Email: saeed.lakho@usindh.edu.pk \\ Received 12 March 2021, Revised 18 April 2021, Accepted 19 April 2021
}

\begin{abstract}
Metal oxide nanoparticles have found numerous applications in different fields. In this paper, the preparation of nickel oxide nanos tructures is given. The nanostructures were synthesized by using the hydrothermal method. The characterization was done with X-ray diffraction (XRD) and scanning electron microscopy (SEM). The newly synthesized nanostructures were utilized as a modifier of the working electrode, i.e., glassy carbon electrode (GCE). The modified GCE exhibited an excellent response towards methotrexate (MTX) anticancer drug. The modified GCE, as compared to bare GCE, showed an increased response towards MTX. In this study, BrittonRobinson buffer (BRB) was selected as a supporting electrolyte having $\mathrm{pH}$ 5. By using electrochemical impedance spectroscopy (EIS), the method was found linear in the range of 5-40 $\mu \mathrm{M}$ with a limit of detection and quantification values of $2.4 \mu \mathrm{M}$ and $7.28 \mu \mathrm{M}$, respectively. The method developed by this way was successfully applied for the analysis of MTX from injection formulations. The interference studies were also carried out to check the method's selectivity.
\end{abstract}

Keywords: Nickel Oxide, Nanosutures, Methotrexate, Electrochemical Analysis.

\section{Introduction}

Methotrexate, commonly named MTX (Fig. 1), is the best drug to treat the number of chemotherapies, i.e., head and neck cancer, leukemia, and osteogenic sarcoma [1]. Also, it is reported for indications, i.e., cancer of bladder and breast [2]. However, it can also cause some side effects, including lung and liver disease, low white blood cell counts [3], and could also be life-threatening in case of high dose usage [4]. Analyzing MTX is very much necessary for many reasons. Many methods have been utilized for the detection of MTX. Some methods are HPLC [5, 6], ESIMS [7], fluorimetry [8], and capillary electrophoresis (CE) [9], respectively. All these methods require tedious pre-treatment, time consuming, and highly sophisticated machines that are very costly. That's why an 
economic, less time taking and more sensitive method is always necessitated for analysis of MTX. All these properties are present in electrochemical techniques, which are very easy to use, less time consuming, and economic for analysis of chemicals or pharmaceuticals. MTX has been detected by different modes of electrochemical analysis, i.e., square wave voltammetry [10], differential pulse voltammetry [11], and other electrochemical modes [12-20].

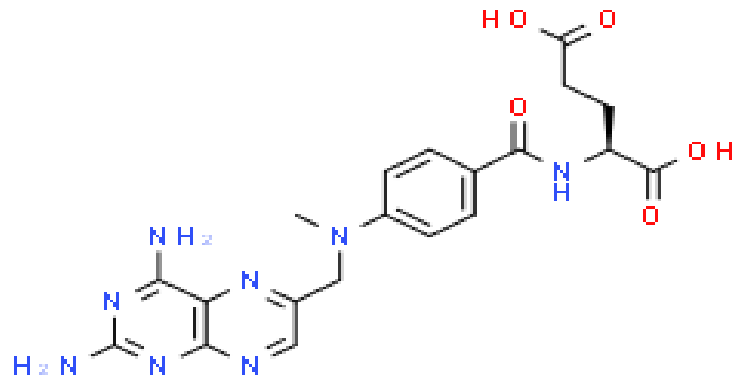

Figure 1. Chemical structure of methotrexate

At the start of the $20^{\text {th }}$ century, the concept for electrochemical impedance spectroscopy (ESI) was given by D. Macdonald [21]. Initially, EIS was carried out to evaluate the capacitance of the electrode, which was ideally polarized. In the mid-1970s, researchers were able to measure full impedance spectra by using the most stable potentiostats. Different mathematical equations for the extraction of data from impedance spectra were developed for nonstationary systems [22-25]. Various researchers have utilized the EIS mode to analyze drugs because of its sensitivity and shorter time of analysis [26-28]. In this paper, we report an easy hydrothermal method for the synthesis of nickel oxide nanostructures (NiONSs) and the use of these newly synthesized materials as a modifier of GCE for electrochemical detection of MTX. The $\mathrm{CV}$ and EIS modes were used for the electrochemical characterization of the sensor. A method was developed using the sensor to detect MTX and successfully applied for analysis of MTX from pharmaceutical formulations.

\section{Materials and Methods \\ Chemicals and Reagents}

All reagents used were without dilution until and unless stated. MTX was purchased from a local pharmaceutical company. Nickel (II) chloride hexahydrate, potassium dichromate, urea, acetic acid, orthophosphoric acid, and boric acid, sodium hydroxide, and methanol were purchased from Sigma-Aldrich. Hydrochloric acid was purchased from Merck millipore. The stock solution of the MTX was prepared as $1 \mathrm{mM}$ in BRB buffer $\mathrm{pH}$ 5. Doubly distilled water with no any ion was used throughout this work.

\section{Synthesis of Nickel Oxide Nanosutures (NiONSs)}

The synthesis of the nickel oxide nanostructures (NiONSs) was carried out using the hydrothermal method. Equal volumes from solutions of $0.1 \mathrm{M}$ nickel (II) chloride hexahydrate and $0.1 \mathrm{M}$ urea were mixed. Then potassium dichromate $(0.1 \mathrm{~g})$ was added to the beaker containing a urea and nickel (II) chloride mixture. The beaker was put in preheated oven at $95{ }^{\circ} \mathrm{C}$. The beaker was taken after $5 \mathrm{~h}$ from the oven, and growth of nanostructures was observed at the bottom of the beaker. The solution was filtered using filter paper followed by air drying. Then the filtrate was calcinated at $500{ }^{\circ} \mathrm{C}$ for $5 \mathrm{~h}$.

\section{Characterization of Nanostructures (NiONSs)}

The sample obtained by the above mentioned method was characterized using two techniques $\mathrm{x}$-ray diffraction (XRD) and scanning electron microscopy (SEM). The XRD was used to study the crystallography of nanostructures by using Bruker (Model: D8 
Advanced) diffractometer at $40 \mathrm{kV}, 40 \mathrm{~mA}$ and $\mathrm{Cu} \mathrm{K \alpha}$ radiation $(\Lambda=0.15406 \mathrm{~nm})$, scanning from $30^{\circ}$ to $80^{\circ}$ at a step of $0.02^{\circ}$. The surface morphology of NiONSs was studied using JEOL (Model: 6380-L) scanning electron microscope.

\section{Electrochemical Analysis of Nanosutures (NiONSs)}

In this study, GCE has been modified with NiONSs and used as a working electrode for electrochemical operation in potentiostat. The GCE was modified using drop casting method. In the first step, NiONSs was weighed up to 5 mg following the addition of water (up to $1 \mathrm{~mL}$ ). The slurry was prepared by vortex mixing the material in water, and then $30 \mu \mathrm{L}$ of Nafion in methanol solution was mixed with this slurry. The mixing was carried out with vortex for 5-10 min. After the slurry was homogenized, $10 \mu \mathrm{L}$ from this slurry was taken out with the help of a micropipette and put on an upright GCE surface. The electrode was dried with warm air for $5 \mathrm{~min}$. Then the modified GCE was utilized as a working electrode for further studies. Potentiostat VersaSTAT-4-500 was used for electrochemical analysis. The station was made up of three electrode system for that $\mathrm{Ag} / \mathrm{AgCl}$ and $\mathrm{Pt}$ wire were used as a reference and counter electrodes, respectively. The NiONSs modified GCE was utilized as a working electrode. An optimum result was observed in $0.04 \mathrm{M} \mathrm{BRB}$ at pH 5.

\section{Results and Discussion}

Characterization of the Nickel Oxide Nanosutures (NiONSs)

The XRD was used to study the crystallography of NiONSs. Fig. 2a shows the XRD pattern of the synthesized nanostructures. The cubic cell crystal structure of NiONSs was confirmed by JCPDS card no. 01-075-0197.
The morphology of NiONSs was investigated using SEM and found nanosheet like open chain porous structure Fig. $2 b$. The nanosheets synthesized by this way were ultrathin having a thickness in between 100 and $150 \mathrm{~nm}$. This structure may increase the surface area of the nanostructures and hence enhance its electrochemical efficiency.

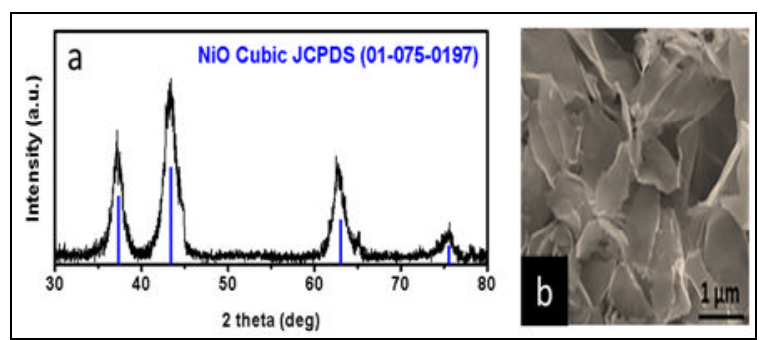

Figure 2. SEM and XRD images for synthesized NiONSs

\section{Electrochemical Behavior of MTX Cyclic voltammetry $(\mathrm{CV})$}

Electrochemical behavior was observed for the MTX in the presence of 0.04 $\mathrm{BRB}$ as supporting electrolyte $\mathrm{pH}$ 5. In the beginning, an amount having $100 \mathrm{mM}$ concentration of MTX was run in the presence of $25 \mathrm{~mL}$ BRB having acidic $\mathrm{pH}$. Following is the CV curve obtained with and without modification of GCE. The response for MTX in the presence of the NiONSs was observed to be more than unmodified/bare GCE as a working electrode. This sensor was given the suffix NiONSsMGCE. The CV curves are given in Fig. 3.

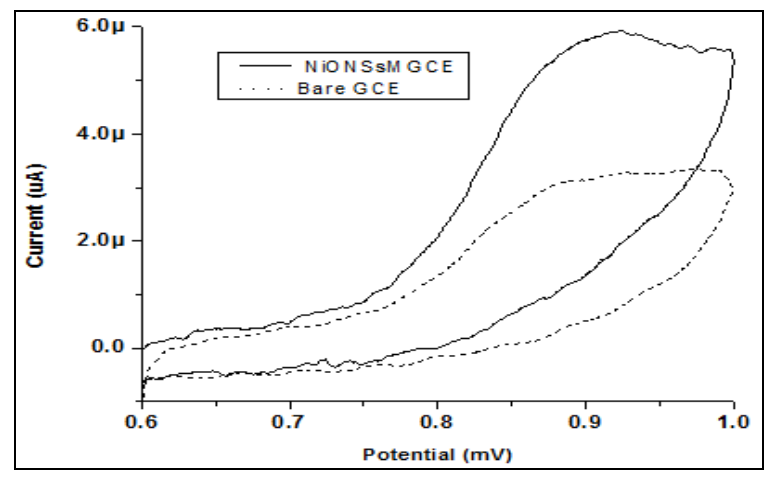

Figure 3. Cyclic voltammetric response for MTX in the presence of bare and modified electrodes 
pH study

Different $\mathrm{pH}$ solutions of BRB were used to get the maximum response of MTX using $\mathrm{CV}$ mode. The range of $\mathrm{pH}$ range checked was between 3-9, respectively. The best response obtained from these $\mathrm{pH}$ values was at $\mathrm{pH} 5$, respectively.

\section{Electro impedance spectroscopy (EIS)}

The electrochemical behavior of the NiONSs MGCE was also studied using electro impedance spectroscopy (EIS) for the detection of MTX. To the best of our knowledge, this is the first method for quantification of MTX from pharmaceutical samples using EIS. EIS was performed from
$0.1 \mathrm{~Hz}$ to $10^{5} \mathrm{~Hz}$ frequency range. The impedance results were analyzed using Z-view software. The impedance data was frequently displayed in Fig. 4a as real impedance ( $\left.Z^{\prime}\right)$ and imaginary impedance (Z"). Then, the impedance data was used to generate complex capacitance data, as shown in Fig. 4b, as a function of the real part of complex capacitance (C') and imaginary part of complex capacitance (C'). By using a complex capacitance curve, the calibration plot was obtained in the range of $5-40 \mu \mathrm{M}$ and found linear, as shown in Fig. 4c. The Limits of detection (LOD) and quantification (LOQ) were found as $2.4 \mu \mathrm{M}$ (39/slope) and $7.28 \mu \mathrm{M}$ (109/slope), respectively, which were calculated by the same method as given by [29].

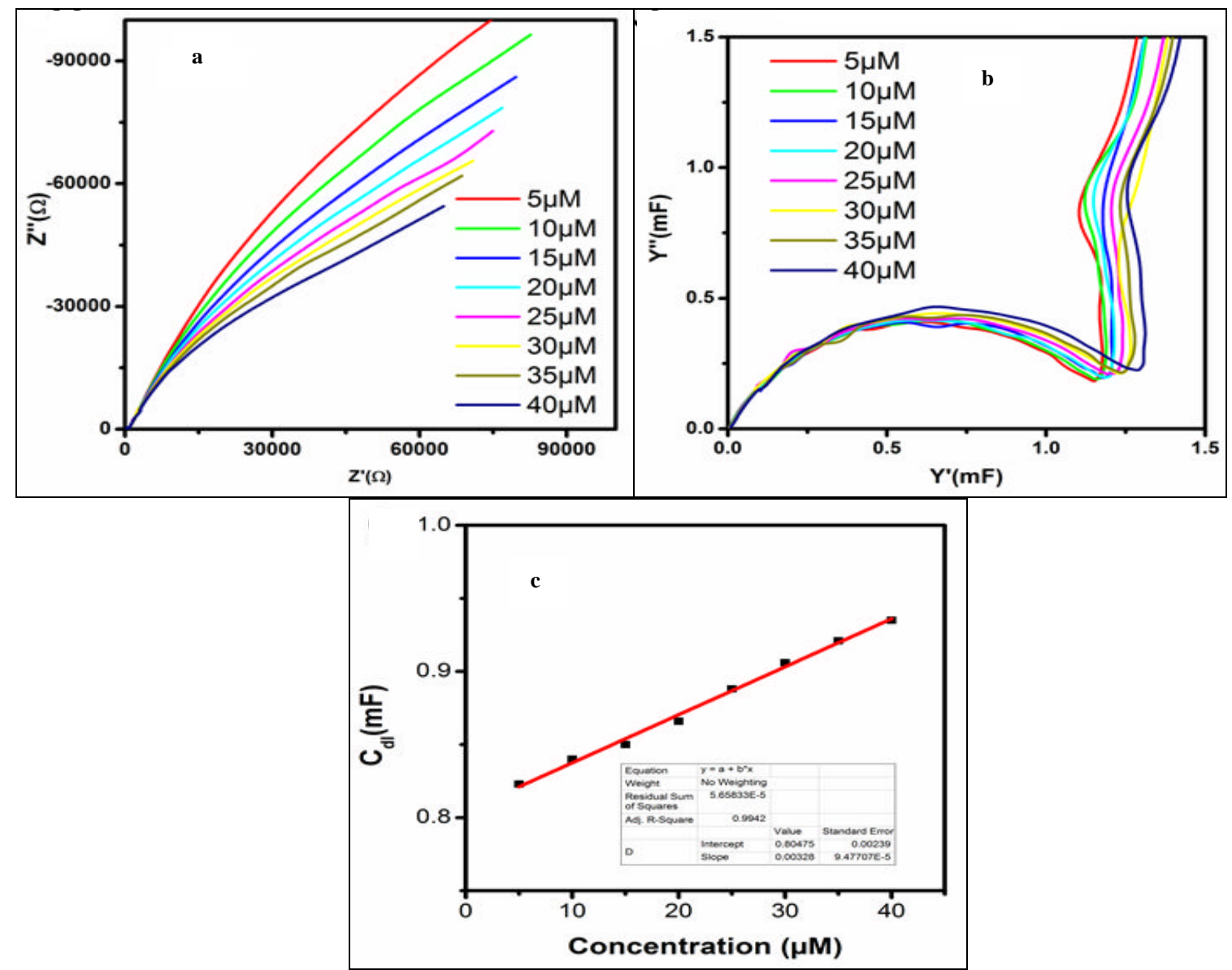

Figure 4. Nyquist plot for calibration (a) Complex impedance plane (b) Complex capacitance plane (c) Calibration curve for MTX using $\operatorname{EIS}(5-40 \mu \mathrm{M} / \mathrm{L})$ 


\section{Application of the developed method}

The newly developed method for analysis of MTX from injection formulations was applied using a calibration curve in $\mathrm{CV}$ mode and EIS. Two injections brands were purchased from a local market, and MTX was assayed from these. The stock solution of 1 mM MTX was prepared in BRB pH 5. The dilutions from these solutions were carried out for analysis. The results obtained from these brands are given in Table 1.

Table 1. The applicability of the New method for Pharmaceutical formulations.

\begin{tabular}{cccc}
\hline Brand & $\begin{array}{c}\text { Added } \\
\text { Amount } \\
(\boldsymbol{\mu M})\end{array}$ & $\begin{array}{c}\text { Found } \\
\text { Amount } \\
(\boldsymbol{\mu M})\end{array}$ & $\begin{array}{c}\text { Relative } \\
\text { Standard } \\
\text { Deviation }\end{array}$ \\
\hline \multirow{3}{*}{ Brand 1 } & 40 & 39.04 & 1.09 \\
& 50 & 50.09 & 1.99 \\
& 60 & 59.95 & 2.03 \\
Brand 2 & 40 & 40.03 & 2.04 \\
& 50 & 50.06 & 1.93 \\
\hline
\end{tabular}

\section{Selectivity studies for new method}

The selectivity of the new method was checked by adding different other possible interfering agents, i.e., anticancer drugs like Mitoxantrone, 5-flurouracil, and other chemicals like glucose, sucrose, etc. The data in the form of percentages were calculated for interference. It can be shown in the table that all these chemicals were not affecting the selectivity of the new method as the maximum allowable limit for the interference of these chemicals was noted below than $\pm 5 \%$. The method was observed to be most selective for MTX Table 2.

Table 2. Tolerance limit was defined as ratio that causes $< \pm 5 \%$ interference.

\begin{tabular}{ccc}
\hline $\begin{array}{c}\text { Interference } \\
\text { Agent }\end{array}$ & Ratio Added & $\begin{array}{c}\text { Percentage } \\
\text { Interference }\end{array}$ \\
\hline Mitoxantrone & $1: 10$ & 0.54 \\
5-Flurouracil & $1: 10$ & 1.3 \\
Glucose & $1: 10$ & 2.9 \\
Sucrose & $1: 10$ & 2.1 \\
\hline
\end{tabular}

Comparison between already published methods

Table 3. The comparative data between the new sensor and already published sensors.

\begin{tabular}{|c|c|c|c|c|}
\hline $\begin{array}{l}\text { Working } \\
\text { Electrode }\end{array}$ & Mode & LDR & LOD & Reference \\
\hline$\overline{\text { MWCNTsMSPE }}^{\mathrm{a}}$ & $\begin{array}{l}\text { CV, } \\
\text { SWV }\end{array}$ & $\begin{array}{c}50 \mu \mathrm{M} \text { to } 10 \\
\mathrm{mM}\end{array}$ & $10 \mu \mathrm{M}$ & 30 \\
\hline $\begin{array}{l}\text { SPE modified } \\
\text { with nano- } \\
\mathrm{Au} / \mathrm{MWNTs-} \\
\mathrm{ZnO}^{\mathrm{b}}\end{array}$ & SWV & $\begin{array}{c}0.02-1 \mu \mathrm{M} \\
\text { and } \\
5 \mathrm{nM}-0.2 \\
\mu \mathrm{M}\end{array}$ & $\begin{array}{c}10 \text { and } 2.5 \\
\mathrm{nM}\end{array}$ & 31 \\
\hline $\begin{array}{l}\mathrm{CoFe}_{2} \mathrm{O}_{4} \text { and } \\
\text { reduced } \\
\mathrm{GOMGCE}^{\mathrm{c}}\end{array}$ & SWV & $\begin{array}{c}0.05-75 \\
\mu \mathrm{M}\end{array}$ & $0.01 \mu \mathrm{M}$ & 32 \\
\hline $\begin{array}{l}\text { Au- } E^{\mathrm{d}} \text { modified } \\
\text { with antibodies }\end{array}$ & $\begin{array}{l}\text { EIS, } \\
\text { MDA }\end{array}$ & $\begin{array}{l}273 \mu \mathrm{M}- \\
2.73 \mathrm{Pm}\end{array}$ & $5 \mathrm{pM}$ & 20 \\
\hline NiONSsMGCE & EIS & $5-40 \mu \mathrm{M}$ & $2.4 \mu \mathrm{M}$ & $\begin{array}{l}\text { This } \\
\text { method }\end{array}$ \\
\hline
\end{tabular}

MWCNTsMSPE ${ }^{\mathrm{a}}$ : Multiwall carbon nanotubes modified screen printed electrode, MWNTs-ZnO' ${ }^{\mathbf{b}}$ : Multiwall nanotubes-Zinc oxide, $\mathbf{G O}^{\mathbf{c}}$ : Grephen oxide modified Glassy Carbon Electrode, $\mathbf{A u}-\mathbf{E}^{\mathrm{d}}$ : Gold electrode

\section{Conclusion}

Nickel oxide nanostructures have been synthesized using a hydrothermal method characterized by SEM and XRD. These nanostructures were utilized for electrochemical analysis of MTX, an anticancer drug. A calibration curve was found linear in range from 5 to $40 \mu \mathrm{M}$ by using electrochemical spectroscopy. The limits of detection and quantification were found as $2.4 \mu \mathrm{M}$ and $7.28 \mu \mathrm{M}$, respectively. Different chemical and instrumental parameters were checked, and the method was successfully applied for the analysis of MTX from pharmaceutical formulations.

\section{Conflict of Interest}

The authors declare no conflict of interest.

\section{References}

1. B. C. Widemann and P. C. Adamson, The Oncologist, 11 (2006) 694. doi:10.1634/theoncologist.11-6-694 
2. F. M. Ballis, J. L. Savitch and W. A. Bleyer, Cancer Res., 43 (1983) 2342. doi: https://doi.org/10.1002/1097-0142

3. J. C. Panetta, A. Wall, P. Ching-Hon, M. V. Relling, W. E. Evans, Clin. Cancer Res., 8 (2002) 2423.

PubMed: 12114448.

4. E. Jabbour, S. O'Brien, H. Kantarjian, G. Garcia-Manero, A. Ferrajoli, F. Ravandi, M. Cabanillas and D. A. Thomas, Blood, 109 (2007) 3214. doi:https://doi.org/10.1182/blood-200608-043646

5. I. Duran Meras, A. Espinosa Mansilla, and M. J. Rodriguez Gomez, Anal. Biochem., 346 (2005) 201.

doi:https://doi.org/10.1016/j.ab.2005.07. $\underline{038}$

6. Y. D. Li, Y. Li, N. S. Liang, F. Yang and Z. P. Kuang, J. Chromatogr. B, 1002 , (2015), 107.

doi:https://doi.org/10.1016/j.jchromb.20 15.08.017

7. A. Barbieri, L. Sabatini, P. Indiveri, R. Bonfiglioli, V. Lodi and F. S. Violante, Rapid Commun. Mass Spectrom., 20 (2006) 1889.

doi: https://doi.org/10.1002/rcm. 2527

8. S. Chen, Z. Zhang, D. He, Y. Hu, H. Zheng and $\mathrm{C}$. He, Luminescence, 22 (2007) 338.

doi: https://doi.org/10.1002/bio.968

9. Z. Szakacs and B. Noszal, Electrophoresis, 27 (2006) 3399.

doi:https://doi.org/10.1002/elps.2006001 28

10. F. Wang, Y. Wang, K. Lu, X. Wei and B. Ye, J. Electroanal. Chem., 674 (2012), 83.

doi:https://doi.org/10.1016/j.jelechem.20 $\underline{12.04 .010}$

11. G. Oliveira, B. Janegitz, V. Zucolotto, and O. Fatibello-Filho, Open Chem., 11 (2013), 1120.

doi:https://doi.org/10.2478/s11532-0130305-5
12. N. Jandaghi, S. Jahani, M. M. Foroughi, M. Kazemipour and M. Ansari, Microchim. Acta, 187 (2020) 24. doi:https://doi.org/10.1007/s00604-0194016-2

13. A. A. Ensafi, F. Rezaloo and B. Rezaei, J. Taiwan Inst. Chem. E, 78 (2017) 45. doi:https://doi.org/10.1016/j.jtice.2017.0 $\underline{5.031}$

14. S. Tesfalidet, P. Geladi, K. Shimizu and B. Lindholm-Sethson, Anal. Chim. Acta., 914 (2016), 1. doi:https://doi.org/10.1016/j.aca.2016.02 .012

15. S. Kummari, S. Kumar, M.Satyanarayana and K. V. Gobi, Microchem. J., 148 (2019) 626. doi:https://doi.org/10.1016/j.microc.201 9.05 .054

16. E. M. Materon, A. Wong, O. FatibelloFilho and R. C. Faria, J. Electroanal. Chem., 827 (2018) 64. doi:https://doi.org/10.1016/j.jelechem.20 $\underline{18.09 .010}$

17. C. Tse-Wei, U. Rajaji, C. Shen-Ming, A. Alsalmee, F. A. Alharthie and C. WenHan, Ultrason. Sonochem., 58 (2019) 104664.

doi:https://doi.org/10.1016/j.ultsonch.20 19.104664

18. H. R. S. Lima, E. A. Farias, P. R. S. Teixeira, C. Eiras and L. C. Nunes, $J$. Solid State Electrochem., 23 (2019), 3153.

doi:https://doi.org/10.1007/s10008-01904406-2

19. J. Chen, B. Fu, T. Liu, Z. Yan and K. Li, Electroanalysis, 30 (2018) 288.

doi:https://doi.org/10.1002/elan.2017006 $\underline{15}$

20. S. Phal, B. Lindholm-Sethson, P. Geladi, A. Shchukarev and S. Tesfalidet, Anal. Chim. Acta, 987 (2017) 15. doi:https://doi.org/10.1016/j.aca.2017.08 .034 
21. D. Macdonald, Electrochim. Acta, 51 (2006) 1376.

doi:https://doi.org/10.1016/j.electacta.20 05.02.107

22. Z. B. Stoynov and B. S. SavovaStoynov, J. Electroanal. Chem., 183 (1985) 133.

doi:https://doi.org/10.1016/0368-

1874(85)85486-1

23. B. S. Savova-Stoynov and Z. B. Stoynov, Electrochim. Acta., 37 (1992) 2353.

doi:https://doi.org/10.1016/0013-

4686(92)85131-4

24. Z. Stoynov, Electrochim. Acta, 37 (1992) 2357.

doi:https://doi.org/10.1016/0013-

4686(92)85132-5

25. Z. Stoynov, Electrochim. Acta, 38 (1993), 1919.

doi:https://doi.org/10.1016/00134686(93)80315-Q

26. J. A. R. Pasqual, J. C. Colpo, L. A. L. Santos and V. C. Sousa, J. Appl. Electrochem., 51 (2021) 463.

doi:https://doi.org/10.1007/s10800-020$\underline{01520-2}$
27. S. Dahiya, P. Pahuja, H. Lgaz and S. Lata, J. Adhes. Sci. Technol., 33 (2019), 1066.

doi:https://doi.org/10.1080/01694243.20 19.1576353

28. I. Pandey, R. Kant, Biosens. Bioelectron., 77 (2016), 715.

doi:https://doi.org/10.1016/j.bios.2015.1 $\underline{0.039}$

29. S. A. Lakho, S. A. Mahesar, A. R. Khaskheli, Sirajuddin, S. T. H. Sherazi, M. S. Jagirani and R. A. Soomro, Sens. Lett., 15 (2017) 371.

doi: http://doi.org/10.1166/s1.2017.3830

30. S. Wang, Z. Qi, H. Huang and H. Ding, Anal. Lett., 45 (2012), 1658.

doi:https://doi.org/10.1080/00032719.20 $\underline{12.677790}$

31. J. Xie, L. Tao, H. Tian, S. Wang, H. Ding and Y. Wang, Sens. Actuators, B. 204 (2014) 360.

doi:https://doi.org/10.1016/j.snb.2014.07 .099

32. J. Chen, B. Fu, T. Liu, Z. Yan and K. Li, Electroanalysis, 29 (2017) 1.

doi:https://doi.org/10.1002/elan.2017006 $\underline{15}$ 